Max-Planck-Institut für demografische Forschung

Max Planck Institute for Demographic Research

Konrad-Zuse-Strasse 1 - D-18057 Rostock · GERMANY

Tel +49 (0) 3812081 - 0; Fax +49 (0) 3812081 - 202;

http://www.demogr.mpg.de

MPIDR WORKING PAPER WP 2004-028

NOVEMBER 2004

\title{
Childlessness and the Concentration of Reproduction in Austria
}

Martin Spielauer (spielauer@demogr.mpg.de)

This working paper has been approved for release by: Vladimir M. Shkolnikov (shkolnikov@ demogr.mpg.de), Head of the Laboratory for Demographic Data.

(C) Copyright is held by the authors.

Working papers of the Max Planck Institute for Demographic Research receive only limited review. Views or opinions expressed in working papers are attributable to the authors and do not necessarily reflect those of the Institute. 


\title{
Childlessness and the Concentration of Reproduction in Austria
}

\author{
Martin Spielauer
}

\begin{abstract}
In this paper we study the changes of reproduction concentration among women, the levels of childlessness, individual factors influencing childlessness, and the contribution of childlessness to the concentration of reproduction in Austria for the female age cohorts 1917-1961. International comparative studies find a decline in the concentration of reproduction in the last century for all western countries, a trend that was reversed for the most recent cohorts that have reached the end of their reproductive period. This reversal was mainly triggered by an increase of childlessness, a result that can be confirmed also for Austria. The country has one of the highest levels of childlessness, both currently and historically, and changes in the level of childlessness are very pronounced. Austria has very low fertility, too; between the world wars it even witnessed the lowest period fertility in the world. While cohort fertility rates peaked during the baby-boom with 2.5 children per women, fertility decreased considerably for more recent age cohorts. The recent changes in fertility can be attributed partly to composition effects resulting from the educational expansion of the last decades. As our analysis shows, even in the times of the baby boom, cohort fertility exceeded the reproductive level only for the lowest of eight different educational groups, and this group is rapidly decreasing in size. Besides the strong impact of educational on cohort fertility, childlessness and concentration measures of reproduction, a detailed study based on micro-census data reveals strong urban-rural differentials in the demographic changes of the last decades. We can conclude that the recent re-increase in reproduction concentration is an entirely urban phenomenon. Micro-census data also allow for the study of intergenerational dynamics. Comparing the educational level of women with their parents' educational attainment, we found a strong positive effect on childlessness of downward mobility in the lower end of the educational spectrum. In the upper end of the educational spectrum we found a strong positive effect on childlessness of upward mobility.
\end{abstract}




\section{Introduction}

This paper is a descriptive study of the changes of reproduction concentration, the levels of childlessness and the contribution of childlessness to the concentration of reproduction in Austria for the female age cohorts 1917-1961. The study is based on census data and two micro censuses of 1996 rep. 2001 which contain retrospective information on births and other characteristics, e.g., the municipality type and province in which respondents lived at the age of 15 .

This paper was mainly inspired by a recent international comparative study by Shkolnikov et. al. (2004) on the concentration of reproduction in cohorts of US and European women (not including Austria). Our paper looks at the Austrian case. While we find very similar general patterns, micro-census data allow a more detailed analysis that includes retrospective individual characteristics like municipality type (at 15) and parental characteristics. The study by Shkolnikov et al. confirms the initial decline in the concentration of reproduction over time in the last century for all western countries, as found in earlier studies (Vaupel \& Goodwin 1987, for Austria: Lutz \& Vaupel 1987). However, it also finds a reversal of this trend for the most recent cohorts that have reached the end of their reproductive period. This reversal was mainly triggered by an increase of childlessness, a result that can be confirmed also for Austria.

We follow the same general scheme of analysis as Shkolnikov et al. (2004). First, we look at overall trends of birth concentration, finding that childlessness is a major component of the recent increase in birth concentration. We then include into the analysis of childlessness individual characteristics like education, profession, place of residence, and their combinations. Consistent with the results of Shkolnikov for the US, we find that in Austria both childlessness and the concentration of reproduction tend to be higher in the most educated groups of women. In addition to Shkolnikov's comparative study, Austrian data allowed for a deeper analysis. In particular, we included two additional variables in our analysis that showed to have a very strong impact on childlessness: the type of municipality in which a woman lived at age 15 and intergenerational educational mobility, that is, if the education levels of the women under study are higher, the same or lower that that of their parents.

Austria provides a particularly interesting case: It is one of the countries with the highest levels of childlessness, both currently and historically, and the changes of the level of childlessness are very pronounced. Austria is also a country with very low fertility, between the world wars Austria even had the lowest period fertility in the world (Frejka \& Sardon 2003). 
While cohort fertility rates peaked during the baby-boom with 2.5 children per women, fertility decreased considerably for more recent age cohorts. These recent changes of fertility can be attributed partly to composition effects due to the educational expansion experienced in the last decades (Spielauer 2004). As our analysis shows, even in the times of the baby boom, cohort fertility exceeded the reproductive level only for the lowest of eight distinguished educational levels, which is a rapidly decreasing group of women.

Besides the strong impact of education on cohort fertility, childlessness and concentration measures of reproduction, a more detailed study based on micro-census data reveals strong urban-rural differentials in the demographic changes observed in the last decades and we can conclude, that the recent re-increase of the concentration of reproduction is an entirely urban phenomena.

Micro-census data also allow for the study of intergenerational dynamics. We found particularly interesting results for women with the lowest educational level. Their level of childlessness differs considerably between mothers with a higher educational attainment and mothers of the same educational level.

\section{Data sources and limitations}

What is the percentage of childless women in Austria and what are the parity progression ratios for higher order births? To answer this question, we use different data sources and methods of calculation that lead to different estimations of childlessness and parity progression rates and also have specific limitations.

One data source frequently used in international comparisons (e.g., Frejka et al. 2001, Shkolnikov et al., 2004) are register data that allow us to calculate parity progression rates from age and parity specific fertility rates. In order to calculate parity progression rates it is essential that the vital statistics registration of births record births by parity and age of mother. This method of registration applies to Austria since 1984 only. Based on these data, childlessness in Austria is estimated to be $23.2 \%$ for the female 1965 birth cohort (Frejka \& Sardon 2003). It is thereby one of the highest in Europe. As Austrian register data do not allow us to construct time series for earlier birth cohorts, this data source will not be used further in this study. 


\begin{tabular}{|c|c|c|c|}
\cline { 2 - 4 } \multicolumn{1}{c|}{} & \begin{tabular}{c} 
CENSUS \\
\multicolumn{1}{c|}{}
\end{tabular} & $\begin{array}{c}\text { MICRO } \\
\text { CENSUS } \\
1996\end{array}$ & $\begin{array}{c}\text { MICRO } \\
\text { CENSUS } \\
2001\end{array}$ \\
\hline $1917-21$ & $17 \%$ & $16 \%$ & $17 \%$ \\
\hline $1922-26$ & $18 \%$ & $18 \%$ & $20 \%$ \\
\hline $1927-31$ & $15 \%$ & $16 \%$ & $19 \%$ \\
\hline $1932-36$ & $12 \%$ & $12 \%$ & $13 \%$ \\
\hline $1937-41$ & $12 \%$ & $9 \%$ & $12 \%$ \\
\hline $1942-46$ & $12 \%$ & $12 \%$ & $11 \%$ \\
\hline $1947-51$ & $12 \%$ & $11 \%$ & $11 \%$ \\
\hline $1952-56$ & $14 \%$ & $13 \%$ & $14 \%$ \\
\hline $1957-61$ & $16 \%$ & $(19 \%)$ & $14 \%$ \\
\hline $1962-66$ & $(19 \%)$ & $(24 \%)$ & $(17 \%)$ \\
\hline
\end{tabular}

Table 1: Percentage of childlessness by birth cohort in different data sources. The numbers in brackets indicate, that corresponding female cohorts have not completed their reproductive period by the time of the survey.

Census data and sample survey data are an alternative data source provided that they include information on parity. Data sources for Austria include the 2001 population census and the special programs of the micro-censuses 1996 and 2001. Estimations based on these data might be biased due to differential mortality and migration besides the common problems of surveys, e.g., non response. The bias can be expected to be highest for the oldest birth cohorts due to different exposure to maternal mortality by parity. (Since 1910, maternity mortality rates have been decreasing from 500 to currently 1-5 deaths per 100,000 life births). In our regression analysis, we excluded women born prior to 1932 . The descriptive results including older cohorts displayed below should be interpreted with caution concerning the older age cohorts. Compared to census data, childlessness is slightly underreported in Micro Census data for the younger age cohorts ${ }^{1}$. Parity progression rates based on census data were published by Hanika (2003); census data used in this study stem from the online-database of the Austrian Statistical Office which allows us to tabulate the female population of 2001 by 5-year age cohorts, parity, and education level.

\section{Descriptive analysis}

\subsection{General fertility dynamics for the female age cohorts 1917-1961}

In the last century, fertility peaked during the baby boom, with an average of 2.5 children per women of the birth cohort 1932-36. The preceding increase in cohort

\footnotetext{
${ }^{1}$ An additional data source available is the Austrian Family and Fertility Survey 1996. As the underrepresentation of childless women in the survey is a known problem of the Austrian FFS, these data were not included in our analysis.
} 
fertility was mainly triggered by the increase of lower order parity progression rates, i.e., a reduction in childlessness and higher parity progressions to second births. After the peak, the decrease of cohort fertility was initially driven by a fast reduction of higher order births and, more recently, by increasing levels of childlessness.

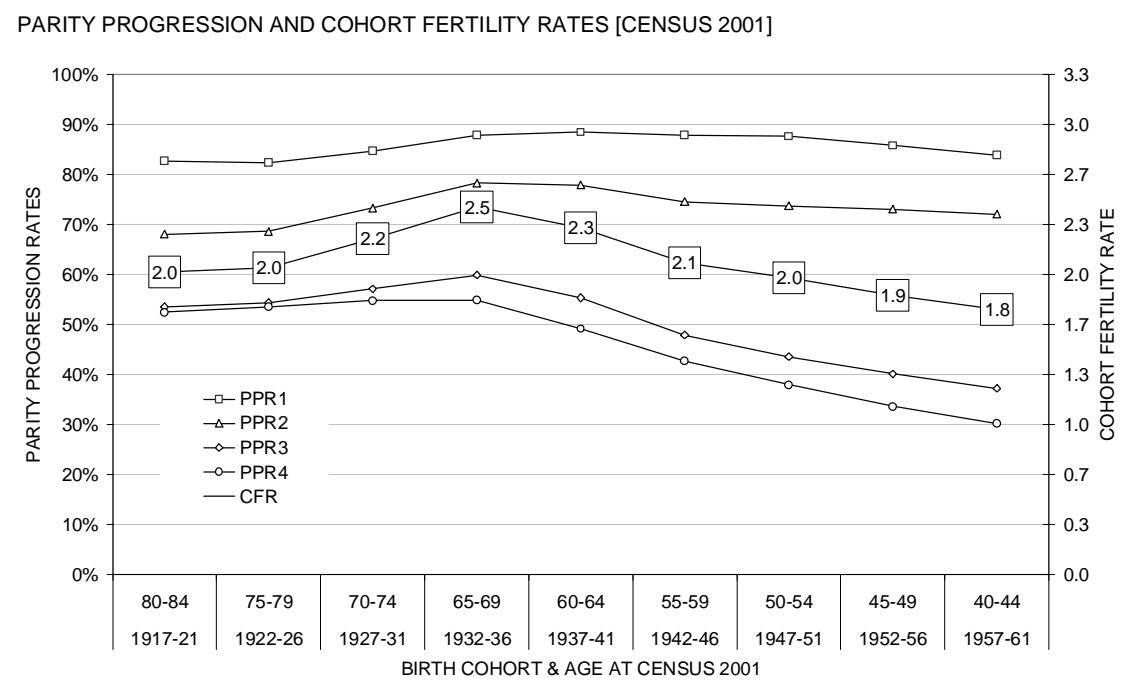

Figure 1: Cohort fertility and parity progression rates calculated from census data

As shown in Spielauer (2003), the changes in lower order parity progression rates in Austria are almost entirely an urban phenomenon: The rates were almost constant for women aged 15 who lived in rural areas. The decline of higher order parity rates, by contrast, is mostly a rural phenomenon: Having more than two children was rather uncommon for women living in urban areas at the age of 15, and also for earlier birth cohorts. 

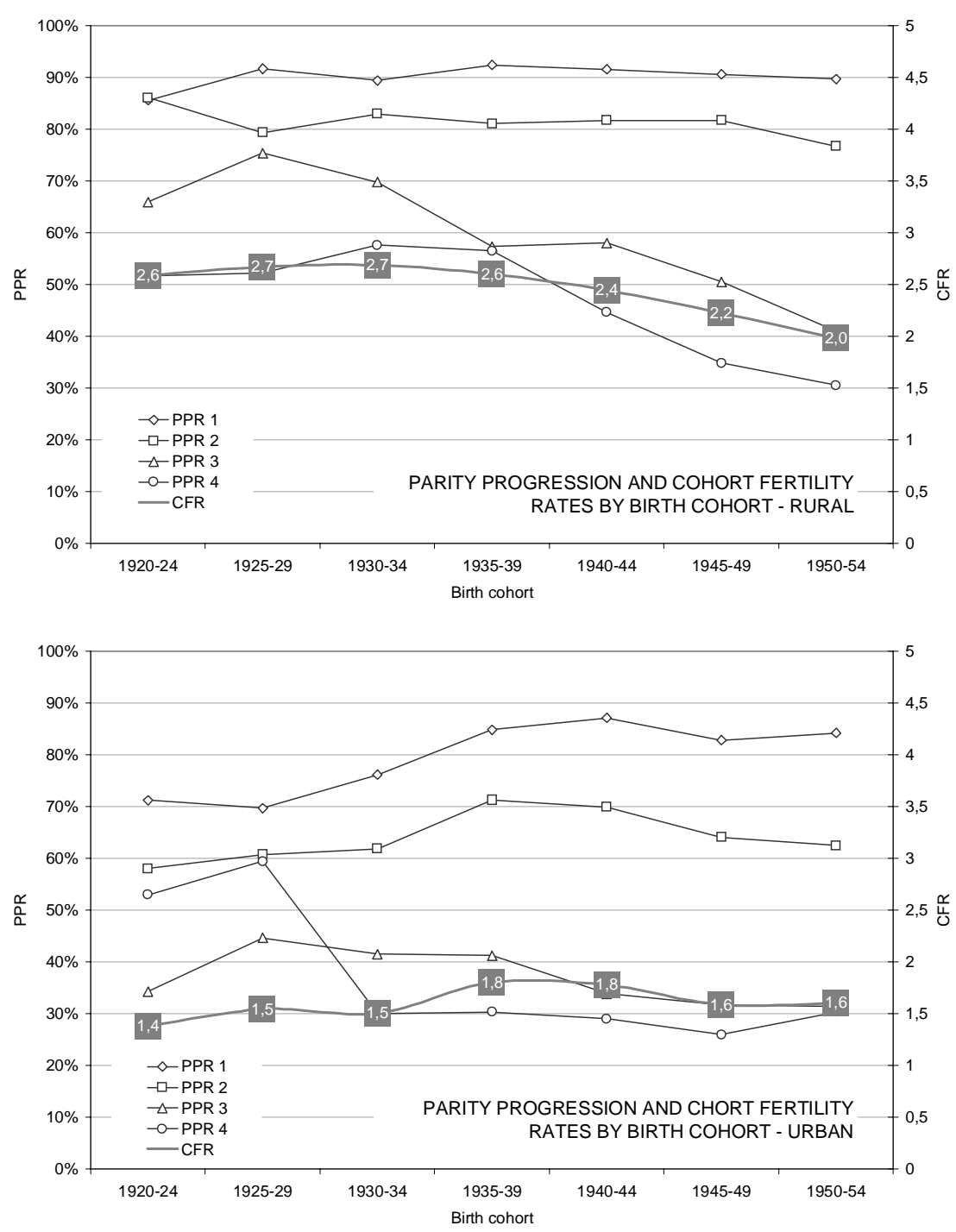

Figure 2: Cohort fertility and parity progression rates by municipality type at age15, calculated from 1996 micro-census data

\subsection{General dynamics of the concentration of reproduction}

The changes in the parity progression rates as outlined above result in changes to the concentration of reproduction, that is, the distribution of the number of children among women of consecutive cohorts. With the emergence of the two child norm, the concentration of fertility decreased, i.e., less women stayed childless and less women gave birth to more than two children. This trend can be observed in all western countries as shown in international comparative studies (Shkolnikov et. al. 2004). In some countries, Austria being one of them, this trend was reversed for recent cohorts, leading to an increased concentration of reproduction mainly caused by rising levels of childlessness.

The concentration of fertility can be measured by the Gini-coefficient (or concentration ratio), which is widely used in economics; other measures which can be 
directly read off from the Lorenz-curve are the Have-Half and Half-Have measures as proposed by Goodwin and Vaupel (1985). The Lorenz curve displays the cumulative percentage of children born by the cumulative percentage of women of a given birth cohort. Have-Half refers to the percentage of women, who have half of the children (around 28\% in the Austrian case, as displayed below). The Half-Have measure refers to the percentage of children born by half of the women (around $75 \%$ in the Austrian case, as shown below). The Gini-coefficient is the area between the Lorenz-curve and the main diagonal divided by the area of the upper triangle. This measure has a theoretical range between 0 (each women has the same number of children) and 1 (all children are born to one woman) and can be interpreted as the average inter-individual difference in the number of children relative to the mean number of children. In this study, we use the Gini-coefficient in order to measure the concentration of reproduction.

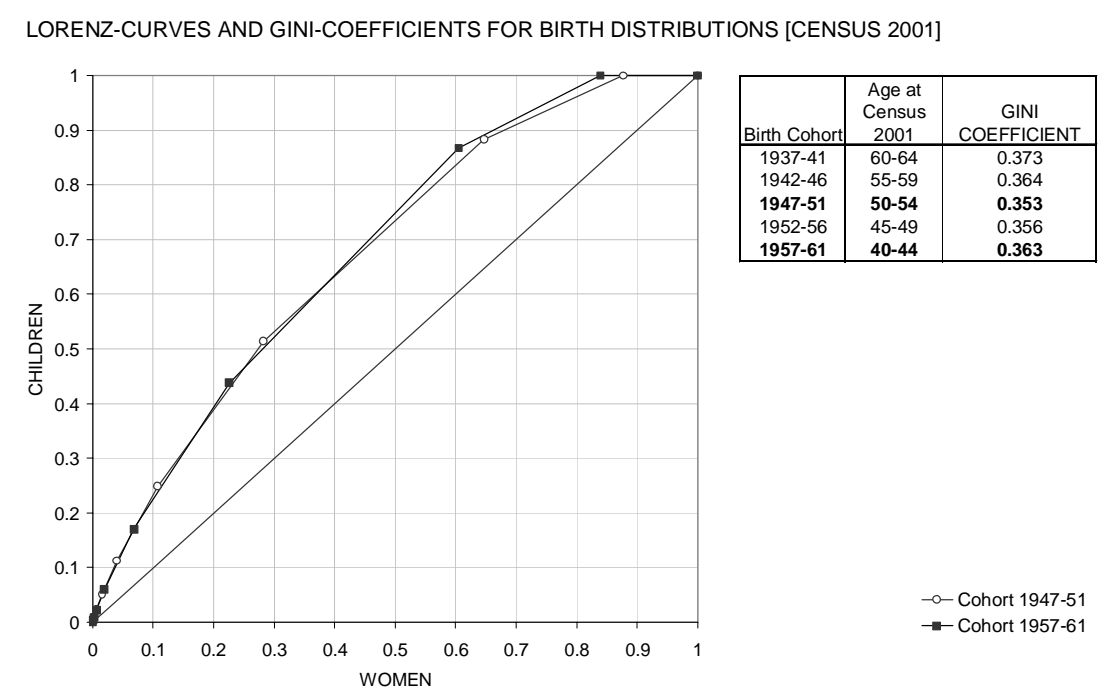

Figure 3: Lorenz Curve and Gini-coefficient for the distribution of births in Austria, calculated from census data

As shown in the figure below, the Gini-coefficient in Austria initially decreased, reaching its lowest level for the birth cohort 1947-51. Thereafter, the Gini-coefficient increased, a reversal of trends that is entirely caused by the recent increase in childlessness, and the Gini-coefficient further decreases if calculated for mothers only. 


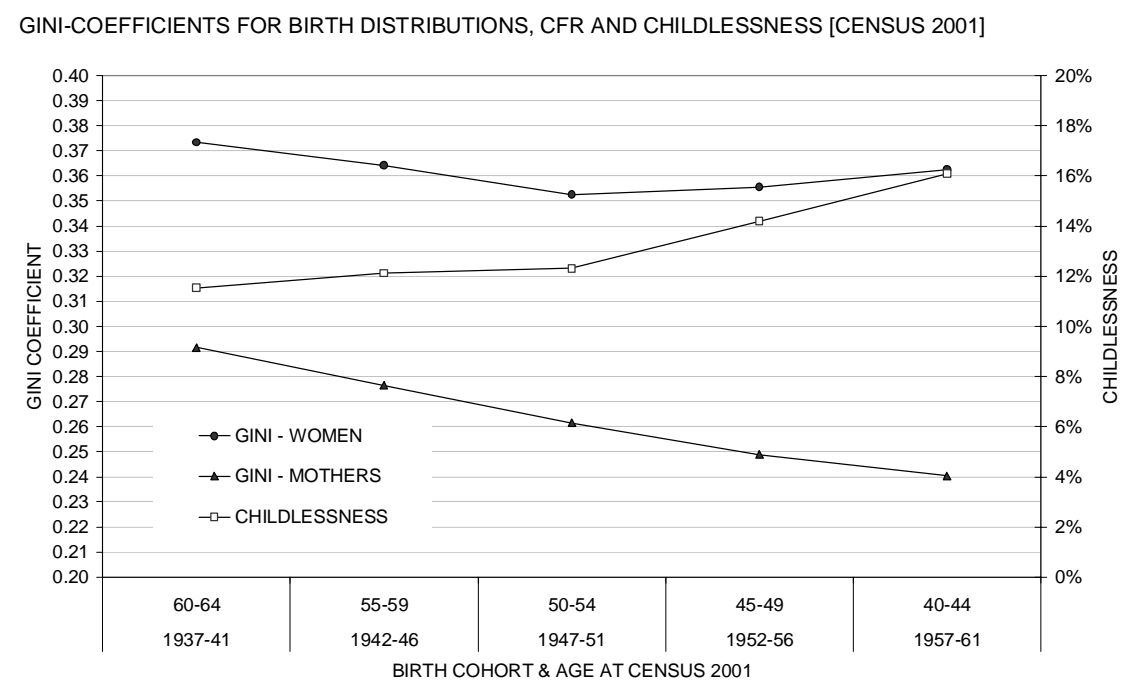

Figure 4: Childlessness and Gini-coefficients for the distribution of births, calculated from census data

\subsection{Fertility dynamics and the concentration of reproduction by educational attainment}

The data of the population census 2001 allow us to distinguish women by educational attainment and, therefore, to conduct a study comparable to Shkolnikov et al. (2004) that has a strong focus on the link between childlessness, the concentration of reproduction, and education. In addition, we are able study the interactions between educational tracks, professions, and childlessness that are especially strong concerning tertiary education. We find very low levels of childlessness for women of tertiary nonuniversity education, an education group that forms an exception to the general ranking of childlessness by educational attainment.

An analysis of changes in cohort fertility over time in Austria reveals considerable educational differentials in fertility. It also shows that the aggregated cohort fertility levels higher than reproduction observed for the middle cohorts were entirely triggered by the high fertility of the lowest of the eight different educational levels. Even in times of high aggregate levels of cohort fertility, no other educational group of women reached reproductive levels of fertility. As the share of women with only compulsory education decreased considerably over time and recently leveled off at around $17 \%$ (Spielauer 2004), the recent fertility decrease can partly be attributed to compositional effects. As can be seen in the graph below, fertility also fell considerably in the compulsory education group while staying comparably stable in other groups or even increasing, as is the case for the second-highest educational group (academies, i.e., non-university tertiary education). The following graph aggregates education levels to five groups. 


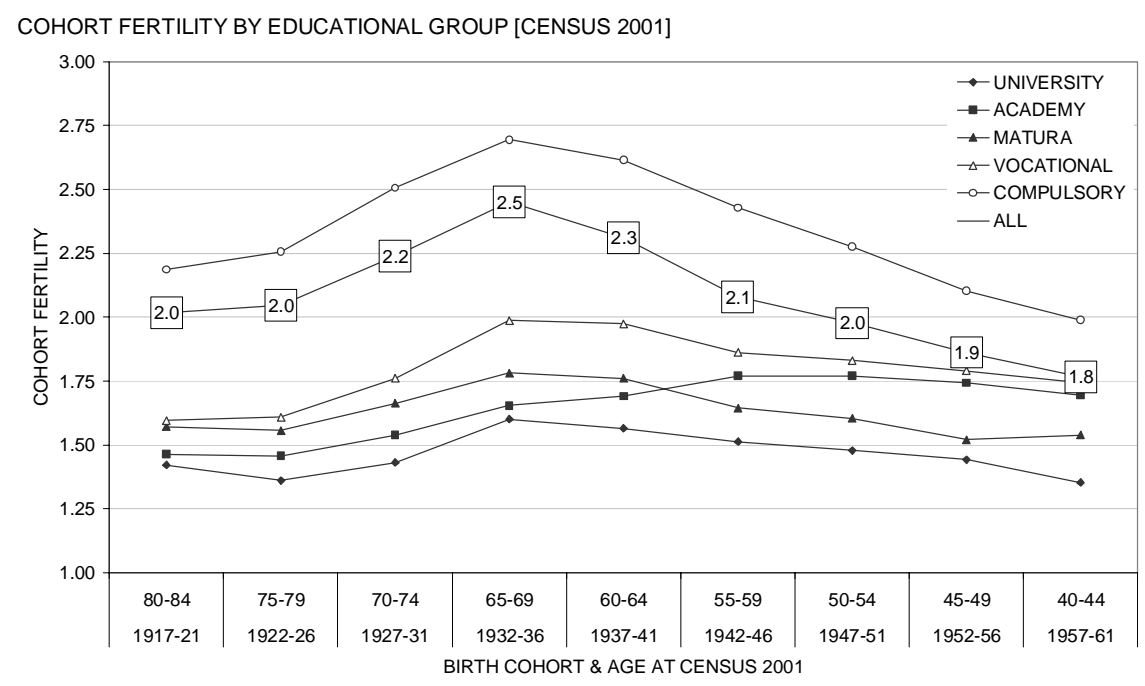

Figure 5: Cohort fertility by educational group, calculated from census data

When comparing the changes in cohort fertility for mothers only, the lines move close together for all but the compulsory education group, indicating that fertility differentials by education in the other groups are highly dominated by different levels of childlessness. For mothers with higher than compulsory education, cohort fertility stays in a narrow range both between educational groups (moving closest together during the baby-boom) and over time staying in the range of 1.9 to 2.3 children per mother.

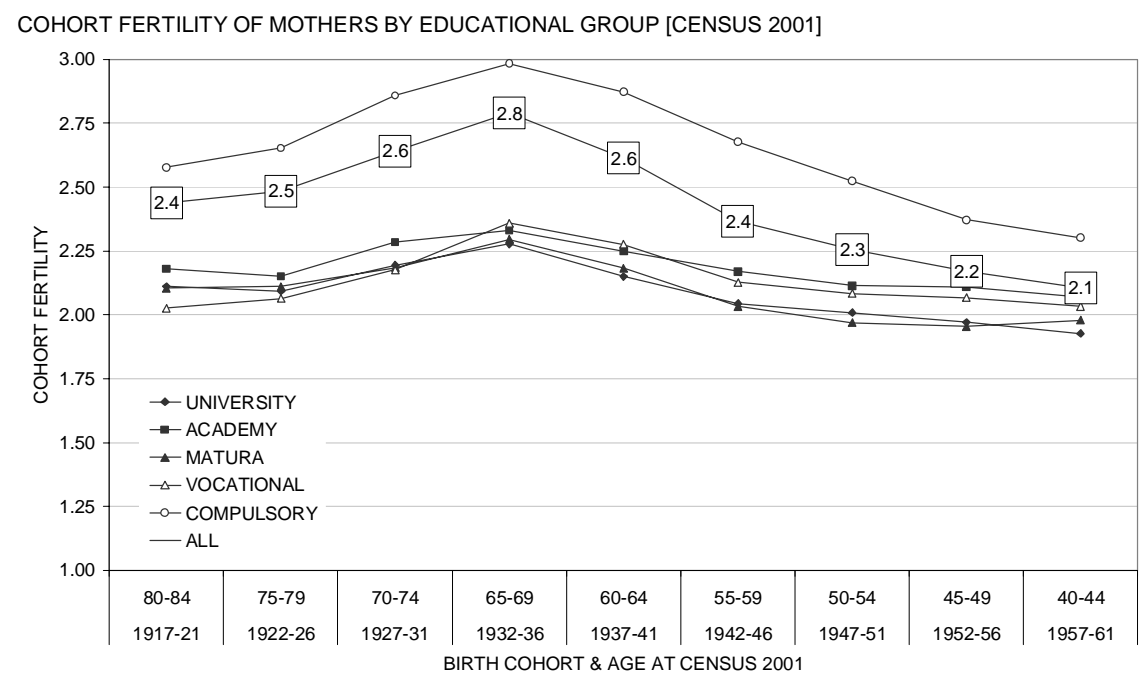

Figure 6: Cohort fertility of mothers by educational group, calculated from census data

Over time, the levels of childlessness range between below $10 \%$ for compulsory education during the baby-boom to above $30 \%$ for the highest educational group of university graduates, both for earlier and recent cohorts. In general, the curves have a U-shape for all educational groups, with the level of childlessness being almost 
perfectly ranked by the educational level. The academy group is an exception. Here, childlessness decreased sharply and crossed the line of the next lower educational group.

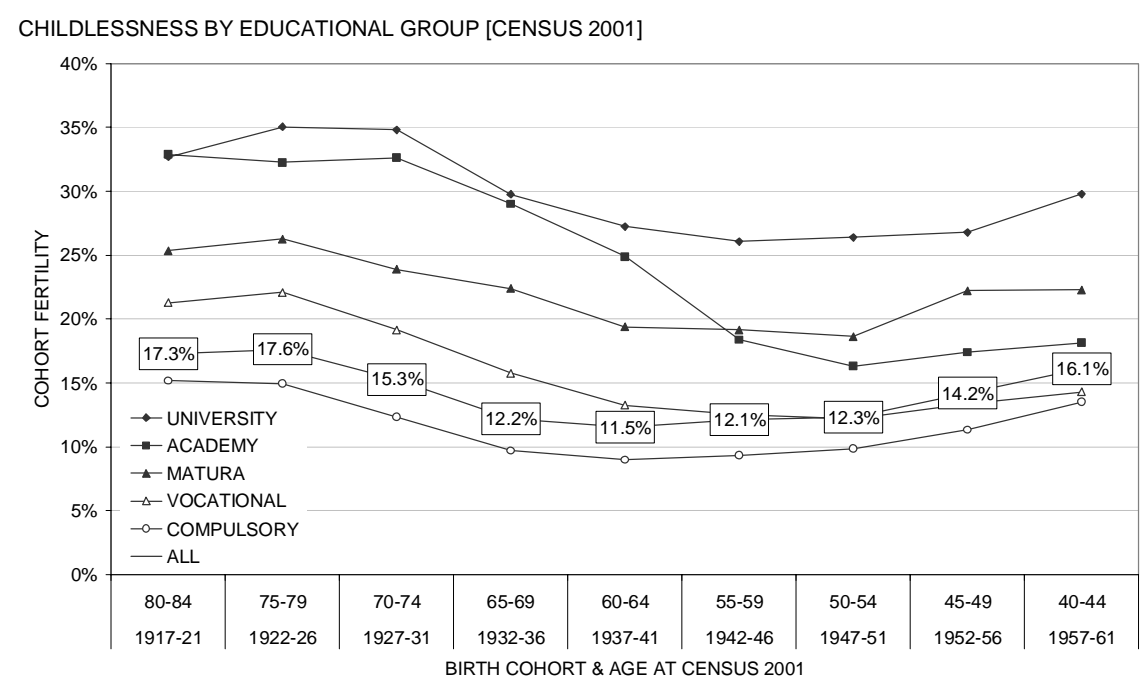

Figure 7: Childlessness by educational group, calculated from census data

A large proportion of academies are training teachers for primary and secondary nonacademic schools, a profession that for more recent cohorts has very low levels of childlessness. Historically, teachers represented an occupational group with high levels of childlessness due to the high importance of religious schools and nuns in the educational system.

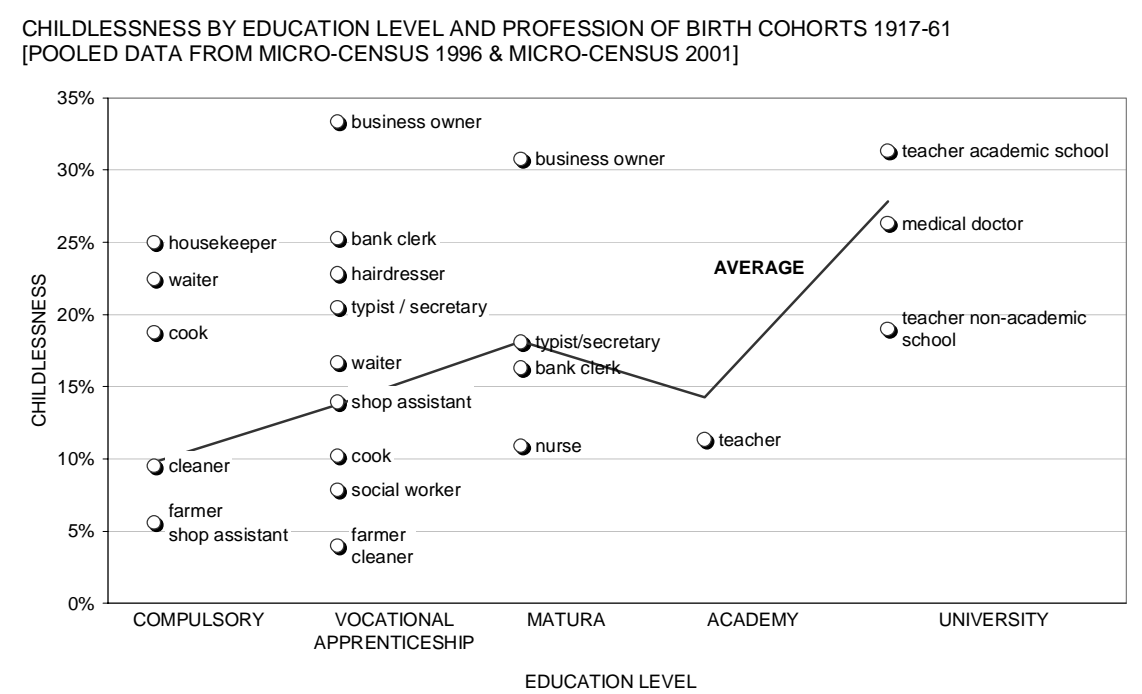

Figure 8: Childlessness by educational group and profession, some significant groups calculated from pooled data of the 1996and 2001 micro-census

The graph above shows the wide dispersion of childlessness by profession within educational groups for cohorts born later than 1917, including the very low level of 
childlessness for teachers trained in academies ${ }^{2}$. For teachers of non-academic schools with university education, childlessness is double as high; for those teaching in secondary academic schools, childlessness is three times higher.

How are the changes in childlessness and cohort fertility by educational group outlined above reflected in the Gini-coefficient of the concentration of reproduction?
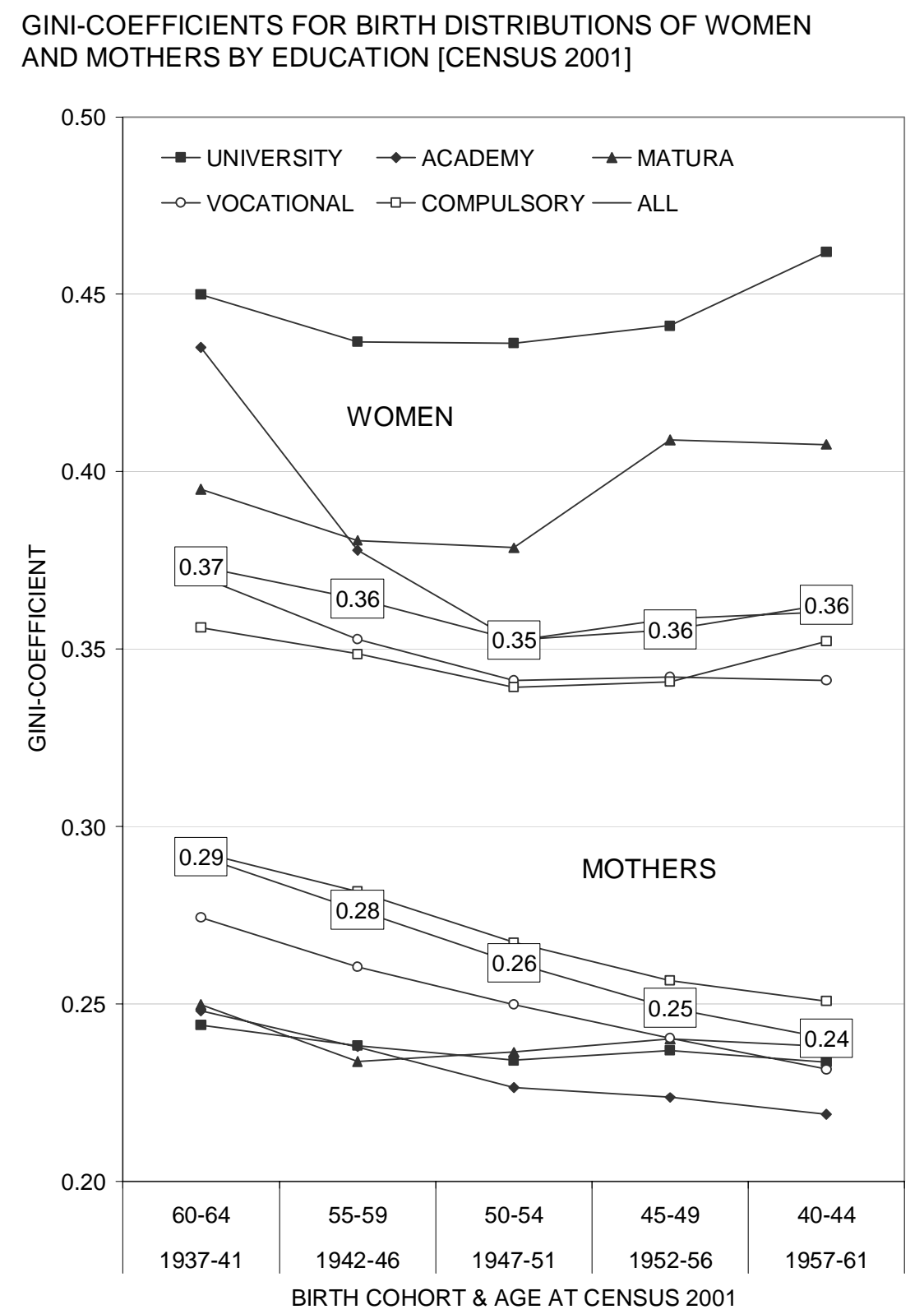

Figure 9: Gini-coefficients for the distribution of births, calculated from census data

As can be seen in the graph above, both the concentration of births and its dynamics over time are different for the different educational groups. We can find two exceptions to the ranking of birth concentration by educational level. The first exception, mentioned above, is the sharp decrease of birth concentration among

${ }^{2}$ Comparable results were found by Hoem et al. (2003) for Sweden. 
graduates from academies who approached average levels of birth concentrations of women and the lowest birth concentration for mothers. The second exception is the slight increase in birth concentration in the lowest educational group for the most recent cohort, for which the compulsory education group now has the second lowest birth concentration of women. As the proportion of women with compulsory education decreased considerably over time, we can hypothesize that this group became a more selective group that can be found increasingly in professional groups with traditionally high childlessness (e.g. waitresses, see Figure 8; as visible from Figure 7, childlessness increased by $50 \%$ in the compulsory education group).

In general, the differences in the concentration of fertility between educational groups are pronounced and persisting when measured for all women, while the recent increase of the Gini-coefficient is highest for higher educational groups. In contrast, no reversals of trends can be found for the concentration of reproduction among mothers. For higher educational groups, the level of concentration leveled off and in general we can observe some convergence between the educational groups.

The following figure summarizes some of the fertility and concentration measures and displays the parity distribution for women of the age group 40-44 at the population census 2001.

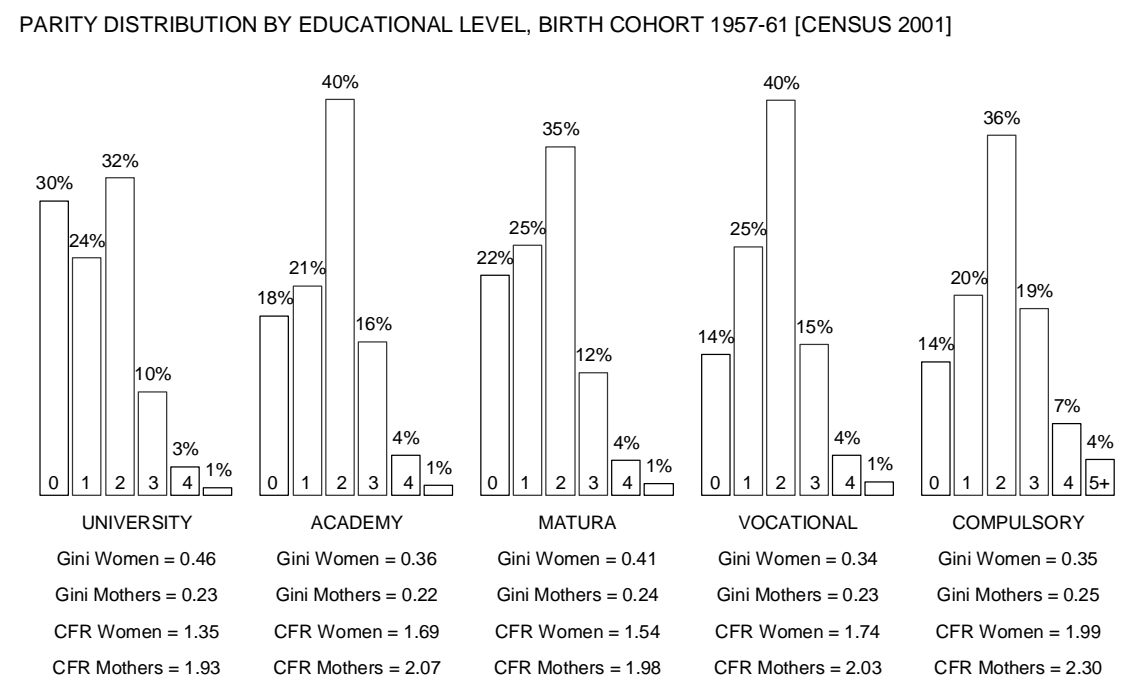

Figure 10: Parity distribution by educational level for women aged 40-44 at the 2001 census, calculated from census data 


\subsection{Fertility dynamics and the concentration of reproduction by municipality type at age 15}

The special program of the 1996 Micro Census includes information on the place of residence at age 15. This information includes the province (incl. an indication whether the person did not live in Austria) and the municipality type, namely "rather rural" vs. "rather urban". considerably in their fertility behavior and dynamics over time: women who lived 1) abroad, 2) in (Austrian) rural municipalities, 3) in (Austrian) urban municipalities except Vienna, and 4) in Vienna ${ }^{4}$.

Considering cohort fertility, we find a clear ranking by municipality type, with the fertility level in the rural group initially lying $85 \%$ higher than in the Vienna group. Cohort fertility decreased in all but the Vienna group, leading to some convergence of fertility levels (the rural group displayed fertility levels $45 \%$ higher than in Vienna in the most recent birth cohort).

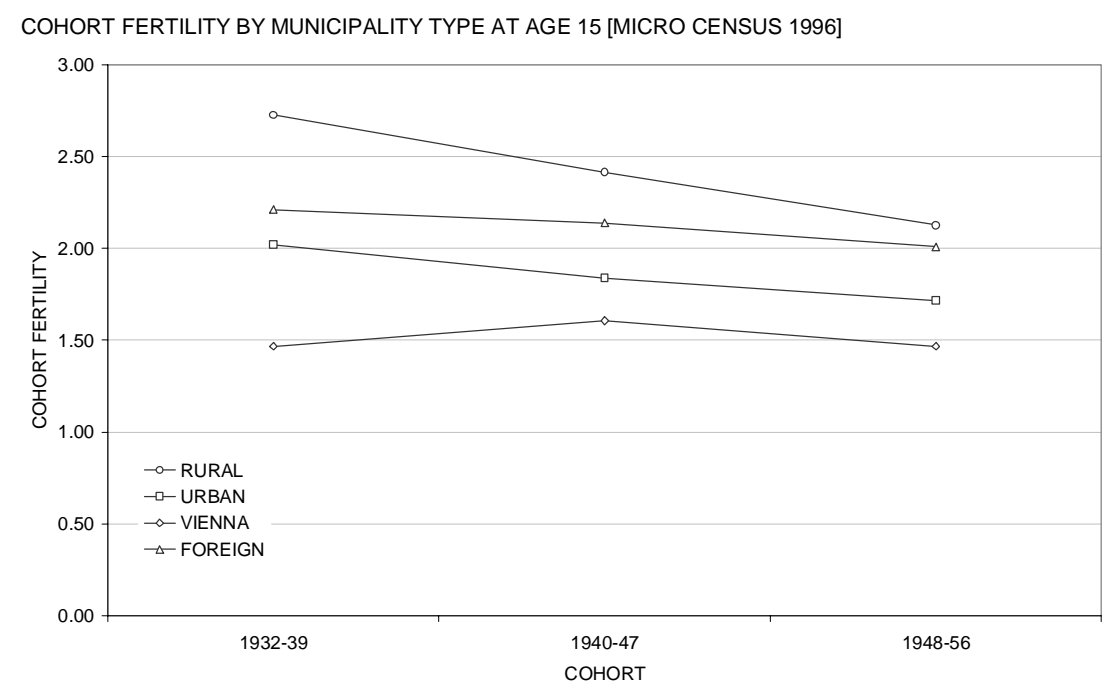

Figure 11: Cohort fertility by municipality type, calculated from 1996 micro-census data

Considering childlessness, we find a very interesting pattern of change by municipality type at age 15, with different trajectories for each group: no change in the rural group, an initial increase that leveled off in the urban group, a decrease in the foreign group and a U-shape for the Vienna group. We conclude that the U-shape found in aggregated data is an entirely urban phenomenon (incl. Vienna) in the phase

\footnotetext{
${ }^{3}$ This information is based on self-evaluation. The share of people indicating that they lived in urban municipalities coincides approximately with the share of people currently living in municipalities greater than 10.000 inhabitants.

${ }^{4}$ Note that the educational composition is very different for these groups; the contribution and interactions of education and municipality type will be studied in detail in the next chapters.
} 
of decreasing levels of childlessness and a Viennese phenomenon in the subsequent period of rising levels of childlessness.

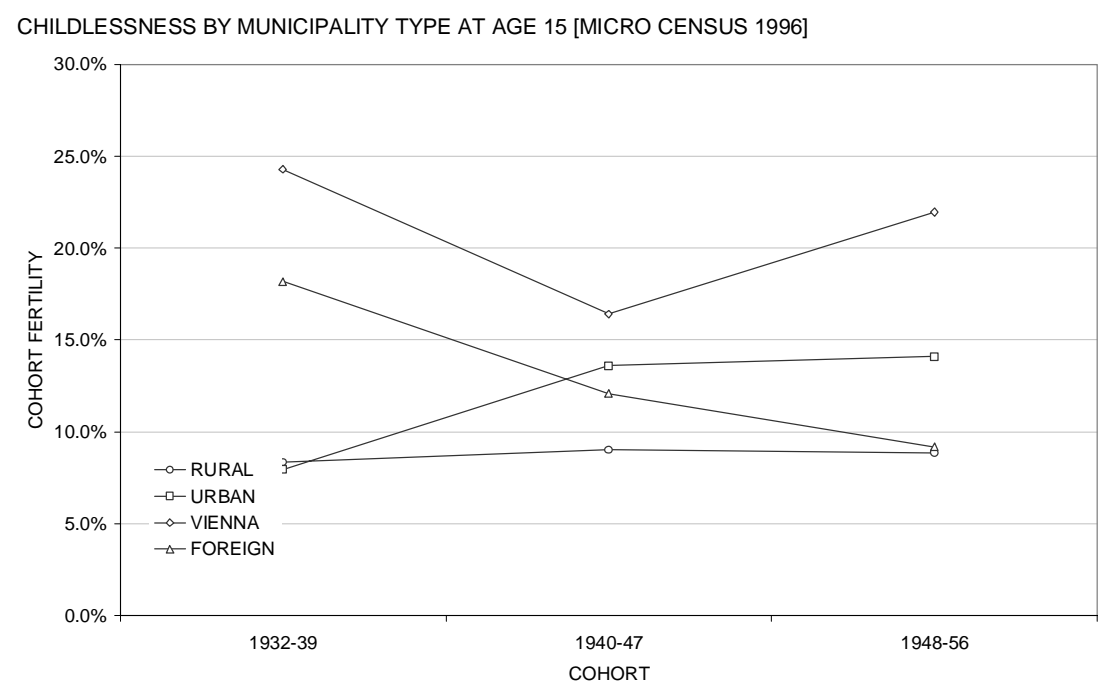

Figure 12: Childlessness by municipality type, calculated from 1996 micro-census data

To what extent are these dynamics reflected in the Gini-coefficient of reproduction concentration for the different municipality groups? Considering the changes to the Gini-coefficients for mothers, we can observe that the reversal of trends is an entirely urban phenomenon. Thus recent increase in the concentration measure is triggered by two different effects in Vienna and other urban municipalities. In Vienna, the recent increase is entirely an effect of rising levels of childlessness (the concentration decreased for mothers) whereas in other urban areas, it stems from an increasing concentration of reproduction among mothers (with an only very slight increase in childlessness). 
GINI-COEFFICIENTS FOR BIRTH DISTRIBUTIONS OF WOMEN AND MOTHERS BY MUNICIPALITY TYPE AT AGE 15 [MICRO CENSUS 1996]

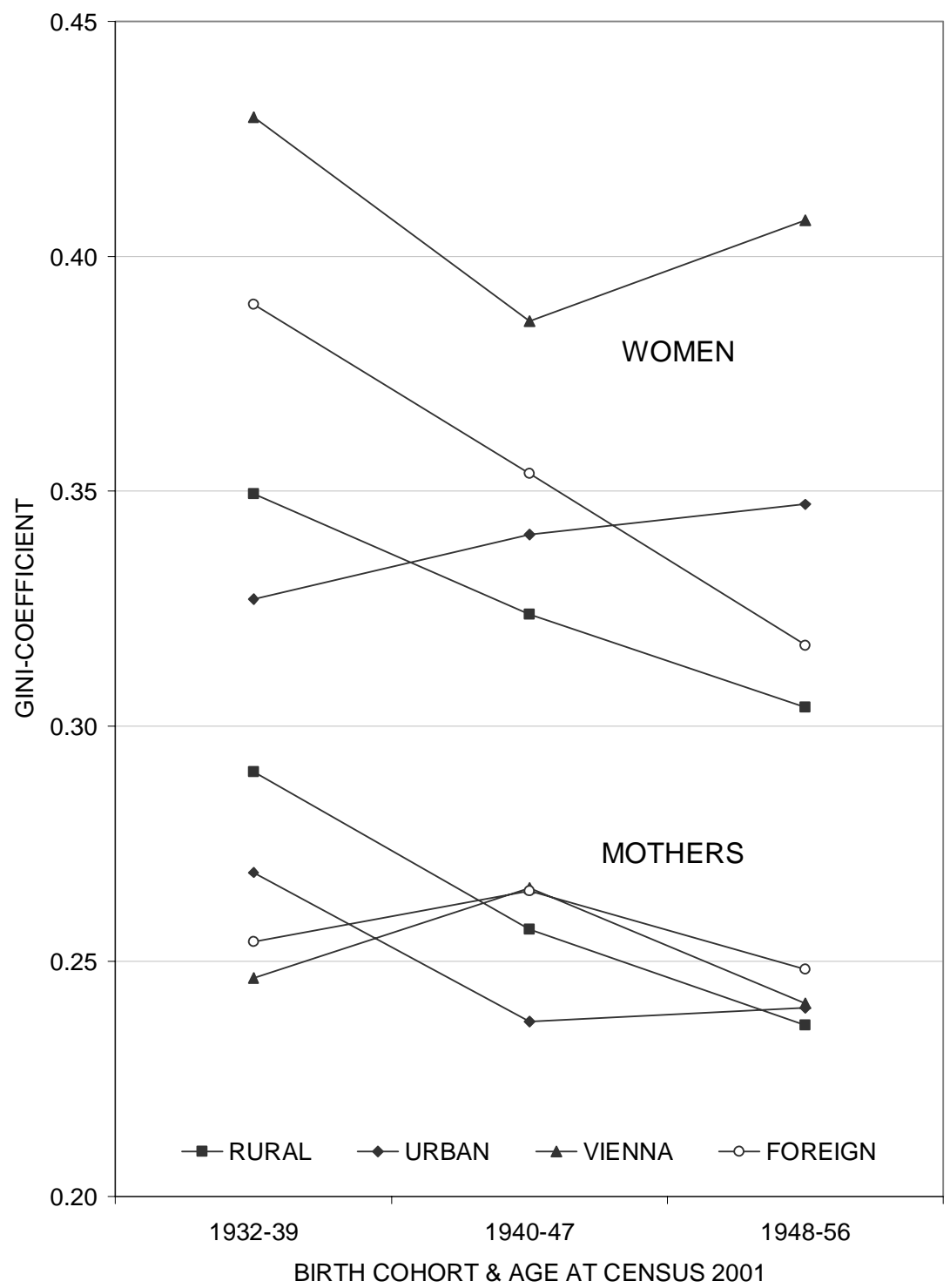

Figure 13: Gini-coefficients for the distribution of births by municipality type at age 15, calculated from 1996 micro-census data 


\section{Logistic regression models for childlessness}

In the following, we develop logistic regression models in order to study the joint effect of the educational level and municipality type as well as other characteristics on childlessness.

\section{Model Variables}

- Birth cohort: (1) 1932-1939, (2) 1940-1947, (3)1948-1956

- Municipality/region at age 15: (1) rural Austria , (2) urban Austria, (3) Vienna, (4) foreign country

- Educational attainment: (1) compulsory education, (2) vocational training or school, (3) Matura diploma (4) academy, and (5) university.

- Interaction of education and intergenerational mobility: (1) compulsory education like at least one parent, (2) compulsory education unlike both parents, (3) vocational training or school, (4) Matura diploma (5) academy, (6) university and at least one parent with tertiary education, and (7) university and no parent with tertiary education.

As starting point, we estimate Model 1 which only includes cohorts and municipality type as explanatory variables for childlessness. We find no cohort effect and a ranking of childlessness by the size of the municipality that a women lived in at the age of 15 . Including the educational level in the model (Model 2) slightly lowers the effect of the municipality type, reflecting different educational compositions within the municipality groups. Again, we do not observe any cohort effects.

The reason why we do not find a cohort effect lies in the aggregation of different trajectories by municipality type, as shown in Figure 12. While in the weighted aggregate we observe U-shaped levels of childlessness, this effect is lost in the first two regression models, mainly due to the under-representation of Vienna in the unweighted sample ${ }^{5}$.

\footnotetext{
${ }^{5}$ The Austrian micro-census is representative on the provincial level, i.e., it has approximately equal sample sizes per province, leading to different average weights between provinces.
} 


\begin{tabular}{|c|c|c|c|c|c|c|c|c|c|}
\hline & M1 & M2 & M3 & M4 & \begin{tabular}{|l|} 
M4 \\
RURAL
\end{tabular} & \begin{tabular}{|l|} 
M4 \\
URBAN \\
\end{tabular} & \begin{tabular}{|l|} 
M4 \\
VIENNA \\
\end{tabular} & \begin{tabular}{|l|} 
M4 \\
FOREIGN \\
\end{tabular} & M5 \\
\hline Cohort 1932-39 & 1 & 1 & & & & & & & \\
\hline Cohort 1940-47 & 0.97 & 1.02 & & & & & & & \\
\hline Cohort 1948-56 & 1.03 & 0.98 & & & & & & & \\
\hline Rural & 1 & 1 & & & & & & & \\
\hline Urban & 1.53 *** & $1.32 * * *$ & & & & & & & \\
\hline Vienna & $2.59 * * *$ & $2.11 * * *$ & & & & & & & \\
\hline Foreign & $1.29 *$ & 1.19 & & & & & & & \\
\hline Rural-Cohort 1932-1939 & & & 0.92 & 0.97 & 0.99 & & & & 0.99 \\
\hline Rural Cohort 1940-1947 & & & 1.00 & 1.00 & 1.00 & & & & 1.00 \\
\hline Rural Cohort 1948-1956 & & & 0.98 & 0.91 & 0.91 & & & & 0.90 \\
\hline Urban Cohort 1932-1939 & & & 0.89 & 0.79 & & $0.58 *$ & & & 0.84 \\
\hline Urban Cohort 1940-1947 & & & $1.58 * * *$ & $1.34 *$ & & 1.00 & & & $1.34 *$ \\
\hline Urban Cohort 1948-1956 & & & $1.66 * * *$ & $1.36 * *$ & & 1.04 & & & $1.39 * *$ \\
\hline Vienna Cohort 1932-1939 & & & $3.31 * * *$ & $2.75 * * *$ & & & $1.71 *$ & & $2.64 * * *$ \\
\hline Vienna Cohort 1940-1947 & & & $2.00 * * *$ & $1.61 * *$ & & & 1.00 & & $1.53 * *$ \\
\hline Vienna Cohort 1948-1956 & & & $2.85 * * *$ & $2.24 * * *$ & & & 1.41 & & $2.34 * * *$ \\
\hline Foreign Cohort 1932-1939 & & & $2.25 * *$ & $2.06 * *$ & & & & 1.52 & $2.19 * *$ \\
\hline Foreign Cohort 1940-1947 & & & 1.38 & 1.21 & & & & 1.00 & 1.14 \\
\hline Foreign Cohort 1948-1956 & & & 1.01 & 0.92 & & & & 0.70 & 0.93 \\
\hline Compulsory & & 1.00 & & 1.00 & 1.00 & 1.00 & 1.00 & 1.00 & \\
\hline Vocational & & $1.35 * * *$ & & $1.35 * * *$ & $1.54 * * *$ & 0.96 & 1.43 & 0.95 & \\
\hline Matura & & $1.80 * * *$ & & $1.80 * * *$ & $1.86 * * *$ & $1.84 * *$ & 1.50 & 1.28 & \\
\hline Academy & & 1.43 & & 1.40 & 1.06 & 1.00 & 1.00 & $7.68 * * *$ & \\
\hline University & & $2.80 * * *$ & & $2.77 * * *$ & $2.74 * * *$ & $2.98 * * *$ & $2.36 * *$ & 2.19 & \\
\hline Compulsory - like mother or father & & & & & & & & & 1.00 \\
\hline Compulsory - both parents higher education & & & & & & & & & $2.08 * *$ \\
\hline Vocational & & & & & & & & & $1.41 * * *$ \\
\hline Matura & & & & & & & & & $1.88 * * *$ \\
\hline Academy & & & & & & & & & 1.45 \\
\hline University - parent(s) with tertiary education & & & & & & & & & $1.82 *$ \\
\hline University - no parent with tertiary education & & & & & & & & & $3.54 * * *$ \\
\hline Observations & 6637 & 6637 & 6637 & 6637 & 419 & 126 & 601 & 578 & 6363 \\
\hline Pseudo R ${ }^{2}$ & 0.0147 & 0.0226 & 0.0179 & 0.0256 & 0.008 & 0.023 & 0.0137 & 0.0345 & 0.027 \\
\hline
\end{tabular}

Table 2: Odds ratios of logistic regression models for childlessness

In Model 3, we account for the different trajectories of childlessness that we observed for the different municipality groups, i.e., no change in the rural group, an initial increase that leveled off in the urban group, a decrease in the foreign group and a Ushape for the Vienna group. This model of cohort-municipality interactions is a representation of the descriptive findings already displayed in Figure $\mathbf{1 2}$ by means of odds ratios.

We include in Model 4 the educational level of the previous model. We obtain almost exactly the same odds ratios for the educational groups as in Model 2, whereas the effect of the municipality-cohort variables slightly decreases (as between Models 1 and 2) without any modification to the general pattern of the trajectories. We can therefore conclude that the patterns of change of the municipality-cohort variable are autonomous changes rather than caused by compositional effects due to changing educational compositions within and between the different municipality groups.

In the following four models (M4 RURAL, M4 URBAN, M4 VIENNA, M4 FOREIGN), we estimate Model 4 separately for each level of the municipality variable. The results reveal some interesting differences in the impact of educational 
attainment on childlessness in the different municipality groups. The trajectories of the cohort-effects, however, remain virtually unchanged. For women who - at age 15 - lived in rural areas, childlessness is significantly higher for all non-compulsory educational groups except academies and, except for academies, ranked by educational attainment. In the urban group, childlessness does not differ between the lowest two educational groups and academies. The odds ratios are double as high for the Matura group and 3 times higher for university graduates. In Vienna, the odds ratio is comparably high (and significant) for university graduates (2.36), whereas all other odds ratios have the expected ranking by educational attainment but without being statistically significant different from the lowest educational group. Women who did not live in Austria at age 15 have high levels of childlessness in the academy and university group only. Different to all other groups, the odds for the academy group are very high due to the small sample of this group ( 9 women). This might be a random effect only.

We study in Model 5 the interaction of the intergenerational dynamics of educational attainment and one's own educational attainment in the lowest and highest educational group (no significant effects were found for other groups). A distinction is made between women of the compulsory group whose mothers or fathers belong to the same educational group from women whose parents have a higher education. We find that childlessness is double as likely for the second group and therefore among the highest of all groups except for university graduates whose parents do not have tertiary education ${ }^{6}$. The strong effect of intergenerational educational downward mobility is also observed in the rate of never married women, which is also double as high in the second group (not shown here). The reverse interaction effect between education and intergenerational mobility can be observed for university graduates: When none of the parents had tertiary education, childlessness was double as high. This indicates high selectivity of this upward mobile group and, thereby, of both upward and downward mobile groups at the upper and lower end of the educational spectrum. Educational downward mobility might be an indicator of the presence of other factors and disadvantages, e.g., health problems, and women of this group can also be expected in occupational groups with high levels of childlessness, e.g., waiters. At the upper end of the educational spectrum, we can expect a higher careerorientation in the upward-mobile group. This group might also face greater economic constrains concerning their studies leading to longer study durations and therefore further postponement of births often not recovered. In fact, the rate of woman with interruptions of more than one year in their education career is double as high for the upward mobile group compared to other university graduates (15\% vs. 7,5\%) whereas

\footnotetext{
${ }^{6}$ An even stronger effect was found for women of the compulsory group with mothers in leading job positions.
} 
we did not find any differences in the distribution of the study durations of students without interruptions.

\section{Summary}

In this contribution, we explored changes in the concentration of reproduction and the contribution of childlessness to this phenomenon. Using micro-data, we studied the impact of the individual-level factors education, occupation, municipality type and parents' education on childlessness. Our results are mainly of a descriptive nature and as such leave room or indicate the need for in-depth analysis and theorizing.

In the last century, fertility peaked during the baby-boom. This peak was preceded by an increase in lower order parity-progression rates and followed first by decreasing higher-order parity progression rates and more recently a re-increase of childlessness to the high levels observed at the beginning of the last century. These changes led to changing patterns in the concentration of reproduction (measured by the Ginicoefficient) among women and also among mothers. We first observed a general decrease in the concentration of births that was reversed for more recent cohorts. This reversal is entirely caused by increasing levels of childlessness, as the concentration of births among mothers decreased for the whole observed period.

We have shown that the changing levels of childlessness are an entirely urban phenomenon, whereas the decrease of higher-order births was mainly a rural one: Higher-order births were few in cities over the whole period. While childlessness initially decreased in all urban areas, the increase that followed is mostly a Viennese phenomenon, as childlessness almost leveled off in other urban municipalities. As a result, the recent increase in the concentration of births also is an urban - and mainly Viennese - phenomenon, something not observed for women who (at age 15) lived in rural areas or abroad.

When including educational attainment in our analysis, we find that even in the cohort with the highest cohort fertility ( 2.5 children) only the lowest of the eight different educational groups had a cohort fertility higher than two. With educational expansion, the size of this group of women decreased rapidly, thus accelerating the fertility decrease by the resulting composition effect. While fertility differentials by education level persist, these differentials are mainly the result of different levels of childlessness, whereas cohort fertility levels for all mothers with an education higher than compulsory stays in a narrow range. While the cohort fertility fell well below reproductive levels, the two-child norm persists as norm for mothers.

For all educational levels, there exist considerable differences of childlessness by profession. An interesting interaction between profession and educational track can be found for teachers. While childlessness is very low for teachers trained in academies 
$(10 \%)$, it is double as high for teachers trained at universities and three times higher for teachers of secondary academic schools (trained at universities). One of the reasons may be the very different study durations of these two educational tracks. Average study durations are extremely long in Austria ( 7.5 years for a master degree compared to 4 years of the regular study duration, and 3 years of study durations in academies) and, considering birth outcome, never recovered.

Childlessness is not only influenced by one's own educational level but also by the difference to parents' education. This effect is very strong in the upper and lower end of the educational spectrum. Childlessness (and the probability of never marrying) is double as high for women of compulsory education who have parents with higher education than for women whose mother or father had compulsory education. For university graduates, we find the reverse effect of upward-mobility. If none of the parents had a tertiary education, childlessness is double as high. This result shows that the general ranking of childlessness by educational attainment is not only superimposed by education-occupation interactions as seen for non-university tertiary education but also by intergenerational educational mobility. Childlessness is highest for university graduates whose parents do not have tertiary education, followed by women with only compulsory education, whose parents have a higher education level.

\section{Acknowledgements}

I am thankful to Vladimir Shkolnikov and René Houle for their comments and to Susann Backer for the careful language editing of this contribution. 


\section{References}

Buber, I. (2001) The effect of the completion of education on entry into motherhood in Austria. Or: The "real" educational catch-up effect". Paper presented at the 5th Annual Conference of the European Society for Population Economics June 2001, Athens University of Economics and Business. Institute for Demography, Austrian Academy of Sciences 2001

Frejka, T. and Sardon, J.P. (2003) Fertility in Austria: past, present and the near future. Vienna Institute of Demography Working Paper 02/2003

Frejka, T; Kingkade, W.W.; Calot, G.; Sardon, J.P. (2001) Cohort childlessness and parity in low-fertility countries. European Population Conference 2001, Helsinki, Finland 7-9 June 2001

Goodwin, D.G. and Vaupel, J.W. (1985) Curves and have-statistics for ecological analysis of diversity. Part III: Comparison of measures of diversity. Working Paper WP-85-91, International Institute for Applied System Analysis, Laxenburg, Austria

Hanika, A. (2003) Volkszählung 2001: Paritäts-Fertilitätstafeln. Statistische Nachrichten, Vol. 58: 90-96, Statistics Austria

Hoem, J.M.; Andersson, G.; Neyer, G.R.; MacGill, J. (2003) Education and childlessness: the impact of the level and type of education on ultimate childlessness in a modern society. Presented at "Tagung der Deutschen Gesellschaft Demographie über Fertilität und Kinderlosigkeit in Europa", Universität

Münster http://www.demogr.mpg.de/publications/files/1573_1075113044_0_Presentation.ppt

Lutz, W. and Vaupel, J.W. (1987) The division of labor for society's reproduction: on the concentration of childbearing and rearing in Austria. Österreichische Zeitschrift für Statistik und Informatik, 17(1-2), 81-95

Shkolnikov, V.M.; Andreev, E.M.; Houle, R.; Vaupel, J.W. (2004) The concentration of reproduction in cohorts of US and European women. Rostock, MPIDR Working Paper WP-2004-027

Spielauer, M. (2003) A dynamic microsimulation model for Austria: general framework and an application for educational projections. Dissertation at the University of Vienna.

Spielauer, M. (2004) Intergenerational educational transmission within families: an analysis and microsimulation projection for Austria. In: Feichtinger, G. (Editor): Vienna yearbook of population research 2004. Vienna: Austrian Academy of Sciences Press, 185-214.

Vaupel, J.W. and Goodwin, D.G. (1987) The concentration of reproduction among US women, 1917-80. Population and Development Review, 13(4), 723-730 